\title{
A COMPARATIVE ANALYSIS OF TWO COMPETING MID-SIZE OXY-FUEL COMBUSTION CYCLES
}

\author{
Egill Thorbergsson;, Tomas Grönstedt \\ Chalmers University of Technology \\ Gothenburg 412 96, Sweden
}

\author{
Majed Sammak, Magnus Genrup \\ Lund University \\ Lund 221 00, Sweden
}

\begin{abstract}
Conceptual turbine and compressor designs have been established for the semi-closed oxy-fuel combustion combined cycle and the Graz cycle. Real gas effects are addressed by extending cycle and conceptual design tools with a fluid thermodynamic and transport property database. Maximum compressor efficiencies are established by determining optimal values for stage loading, degree of reaction and number of compressor stages. Turbine designs are established based on estimates on achievable blade root stress levels and state of the art design parameters. The work indicates that a twin shaft geared compressor is needed to keep stage numbers to a feasible level. The Graz. cycle is expected to be able to deliver around 3\% net efficiency benefit over the semi-closed oxy-fuel combustion combined cycle at the expense of a more complex realization of the cycle.
\end{abstract}

\section{NOMENCLATURE}

A Area.

$c$ Chord.

$C_{m} \quad$ Meridional velocity.

$H$ Stagnation enthalpy.

$M$ Mach number.

$\dot{m}$ Mass flow.

$N$ Rotational speed.

$R$ Gas constant.

$p \quad$ Stagnation pressure.

$P R$ Pressure ratio.

$s$ Entropy.
$T$ Stagnation temperature.

$U$ Blade velocity.

\section{Greek letters}

$\varepsilon$ Tip clearance.

$\varepsilon_{s t r}$ Cooling effectiveness for stator.

$\varepsilon_{r t r} \quad$ Cooling effectiveness for rotor.

$\eta_{p} \quad$ Polytropic efficiency.

$\eta_{s}$ Isentropic efficiency.

$\gamma$ Ratio of constant specific heats.

$\Lambda_{p} \quad$ Reaction degree based on pressure.

$\phi$ Flow coefficient.

$\psi=\frac{\Delta H}{U^{2}} \quad$ Stage loading.

\section{INTRODUCTION}

There is a need for a bridging technology between the current energy system and the sustainable energy system of the future.A large number of technologies are currently being researched to come up with safe, cost efficient and environmentally friendly carbon capture and storage solutions. One approach that shows promise is gas turbine based oxy-fuel combustion cycles. The oxy-fuel combustion fires fuel with pure oxygen instead of air, and the resulting combustion products are primarily steam and carbon dioxide. This makes it technically more feasible to implement $\mathrm{CO}_{2}$ capturing solutions.

Two promising implementations of the oxy-fuel combustion concept are the Semi-Closed Oxy-Fuel Combustion Combined Cycle (SCOC-CC) and the Graz Cycle. In the past, a number of studies on the thermodynamic cycles and conceptual design 
of the turbomachinery have been published. Ulizar presented a study about the SCOC-CC in 1996 [1]. The basic working principle for the Graz cycle was developed by Jericha in 1985 [2]. Since then the Graz cycle has received a considerable amount of research from Graz university as well as other universities, both in regards to cycle analyses and conceptual turbomachinery design [3-7]. There have also been studies that compare the cycles and the conceptual design of the turbomachinery $[8,9]$. This work has, however, mostly addressed the high end of the power output range. In this comparative study we will analyse two cycles targeting a mid-sized version, net output of around $100 \mathrm{MW}$. The reason to study this power range is that in order to battle climate change and fulfill future regulations we need to have carbon capture and storage option available in this range [10].

In the SCOC-CC the main fluid is carbon dioxide. The ratio of specific heats and the gas constant for carbon dioxide are lower than what they are in air. The speed of sound in the working media will be lower than in conventional gas turbines. In the Graz cycle the working fluid is steam and carbon dioxide. For this mixture the ratio of specific heats is slightly lower but the value of the gas constant is higher than for air. This will increase the speed of sound compared to the air based process. These differences will have a profound impact on the design of the gas turbine. The most striking difference related to the working media is that the specific work output is almost two-fold for the Graz cycle. However, looking at the non-dimensional mass flow equation one can see that the impact from the higher gas constant in the working gas of the Graz cycle will result in a lower mass flow per unit area. The optimization study also shows that the efficiency is around 3\% higher. These two benefits are achieved at the expense of a considerably more complex bottoming cycle.

The analysis presented in this paper compares stage loading and geometrical features as well as other gas turbine parameters. The plant performance, net power and net efficiency are included in the comparison. This research is intended to increase the understanding of the turbomachinery design for oxy-fuel combustion cycles and the confidence in the turbomachinery efficiency estimates used in the cycle evaluation of the concepts. One of the problems associated with the Graz cycle is the problem of compressor design. Using single shaft compressor results in quite short compressor exit blades which is difficult to design for keeping a high turbomachinery efficiency and also results in that the compressor will have large numbers of stages. It is therefore suggested to use a twin-spool geared configuration for a Graz cycle with an output in the $100 \mathrm{MW}$ range.

\section{METHOD}

\section{Thermodynamic analysis}

The thermodynamic analysis and process simulations was performed using the commercial software IPSEpro that is developed by SimTech Simulation Technology [11]. The software in-

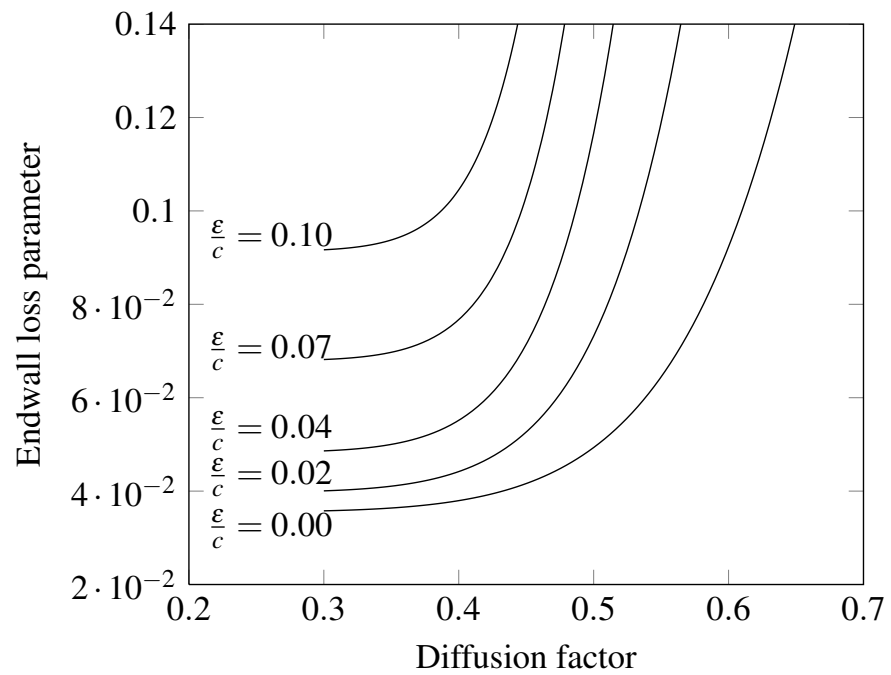

FIGURE 1. CORRELATION FOR ENDWALL LOSS COEFFICIENT [14].

cludes the standard IAPWS-IF97 formulation for pure water and steam [11]. Gas mixtures in IPSEpro are, by default, handled assuming ideal gas behaviour. This necessitated that the software was interfaced with the NIST Reference Fluid Thermodynamic and Transport Properties Database (REFPROP) which uses equations of state and models to calculate gas properties [12]. The cooling method used in the cycle calculations is based on the work by Jordal [13].

\section{Compressor design}

The compressor mean-line design was performed by a Chalmers in-house code. The code uses empirical relations to estimate the losses that are generated. The profile and endwall loss models are based on the work by Wright and Miller [14]. The endwall losses are highly dependent on the diffusion factor. This can be seen in the correlations for the endwall loss in Fig. 1. The figure shows the correlations between the endwall loss parameter, the tip clearance over chord ratio $(\varepsilon / c)$ and the diffusion factor. This dependency will have a strong influence on the optimal compressors established in this paper.

The design code estimates the shock losses using a model developed by Schwenk [15]. A more detailed discussion of the compressor code algorithms and loss model implementation is presented in [16]. The design code uses a method devised by Koch [17] to estimate the static pressure rise coefficient and maximum static pressure rise coefficient for each stage. The difference between these two coefficients indicate how close each stage is to stall/surge.

To handle real gas effects in a consistent way with the IPSEpro cycle tool, the original in-house code has been extended with 
a similar REFPROP interface.

\section{A note on polytropic efficiencies}

Polytropic efficiencies have to be handled with some care when real gas effects are present. The definition of the polytropic efficiency is given by Eq. 1 [18].

$$
\eta_{p}=\frac{d H_{i s}}{d H}
$$

For an ideal gas, Eq. 1 can be integrated using the Gibbs equation to establish an expression relating the polytropic efficiency with the pressure ratio. When the gas properties depend on pressure the process becomes somewhat more intricate. However a numerical integration can be set up that remains consistent with Eq. 1 and reproduces the compressor exit temperature and pressure. This cumbersome approach can be avoided by the use of the empirical expression suggested by the Mallen-Saville model [19]. The Mallen-Saville model assumes that the polytropic path is defined using Eq. 2.

$$
T \frac{d s}{d T}=\text { constant }
$$

The polytropic efficiency can then be calculated using Eq. 3 .

$$
\eta_{p}=\frac{\left(H_{e}-H_{i}\right)-\frac{\left(s_{e}-s_{i}\right)\left(T_{e}-T_{i}\right)}{\ln \left(T_{e} / T_{i}\right)}}{\left(H_{e}-H_{i}\right)}
$$

Aungier reports that the Mallen-Saville model yields excellent accuracy and is fairly easy to implement [20]. This is confirmed by our analysis showing that the model gives less than a $1 \%$ error when compared with the numerical integration. We therefore use the Mallen-Saville method in our calculations.

\section{Turbine design}

The turbine mean line design was carried out by the Lund University in-house turbine design tool LUAX-T. The LUAX-T code is a reduced-order through-flow tool capable of designing highly loaded, cooled turbines. LUAX-T uses the refined Ainely and Mathieson mean-line loss model. The model has been modified by Dunham and Came, Kacker and Okapuu, and finally by Moustapha and Kacker [21]. Loss model comprises profile losses, trailing edge losses, secondary losses and tip clearance losses. For a more detailed discussion see [22].
TABLE 1. COMPOSITION OF THE WORKING MEDIA (S STANDS FOR SCOC-CC).

\begin{tabular}{lllllll}
\hline & \multicolumn{4}{c}{ Composition [\%] } & \multicolumn{2}{c}{$\mathrm{R}$} \\
& $\mathrm{Ar}$ & $\mathrm{CO}_{2}$ & $\mathrm{H}_{2} \mathrm{O}$ & $\mathrm{N}_{2}$ & $\mathrm{O}_{2}$ & {$\left[\frac{\mathrm{J}}{\mathrm{kg} \mathrm{K}}\right]$} \\
\hline Graz Comp. & 1.55 & 20.9 & 77.4 & 0.03 & 0.13 & 400.2 \\
Graz Turb. inlet & 1.74 & 23.6 & 74.5 & 0.04 & 0.15 & 392.3 \\
\hline S. Comp. & 4.06 & 92.0 & 0.98 & 2.86 & 0.12 & 195.5 \\
S. Turb. inlet & 3.82 & 86.5 & 6.91 & 2.68 & 0.11 & 211.5 \\
S. Turb. exit & 3.87 & 87.7 & 5.55 & 2.72 & 0.11 & 207.8 \\
\hline
\end{tabular}

\section{Optimization}

The compressor performance was optimized by varying the stage loading and degree of reaction constraining the diffusion factors. Thus, the optimization space is $2 n$-dimensional where $n$ is the number of stages in the compressor. The objective function was defined by maximizing polytropic efficiency constrained by achieving the required pressure ratio.

The optimization scheme used was a hybrid combination of four optimization methods: a genetic algorithm, Neider and Mead downhill simples, sequential quadratic programming, and a linear solver.

\section{RESULTS Cycle analysis}

The main difference between the two oxy-fuel cycles is that the working fluid in the SCOC-CC is sent to the compressor after the water is separated from the flue gas, whereas in the Graz cycle a large part of the flue gas is recirculated to the compressor. This results in that the major component in the SCOC-CC is $\mathrm{CO}_{2}$ while in the Graz the major component is $\mathrm{H}_{2} \mathrm{O}$. The composition of the working fluid is shown in Table 1.

The fuel is combusted with oxygen that has to be provided to the cycle through an air separation unit. An economically feasible option to produce oxygen in large amounts is through a cryogenic air separation plant $[23,24]$. According to Darde and Amann [25, 26] ASU energy consumption increases drastically when the purity of oxygen goes over $95 \%$. The power consumption necessary to obtain oxygen with $95 \%$ purity and a pressure of $2.38 \mathrm{bar}$ has been assumed to be $900 \mathrm{~kJ} / \mathrm{kg} \mathrm{O}$. An additional $325 \mathrm{~kJ} / \mathrm{kg} \mathrm{O}$ was assumed for its compression [27]. The production of 200 bar liquefied carbon dioxide that is needed to enable transport and storage was assumed to require another $350 \mathrm{~kJ} / \mathrm{kg} \mathrm{CO}$ [27]. The fuel for both cycles is natural gas with a lower heating value of around $48 \mathrm{MJ} / \mathrm{kg}$ natural gas. 


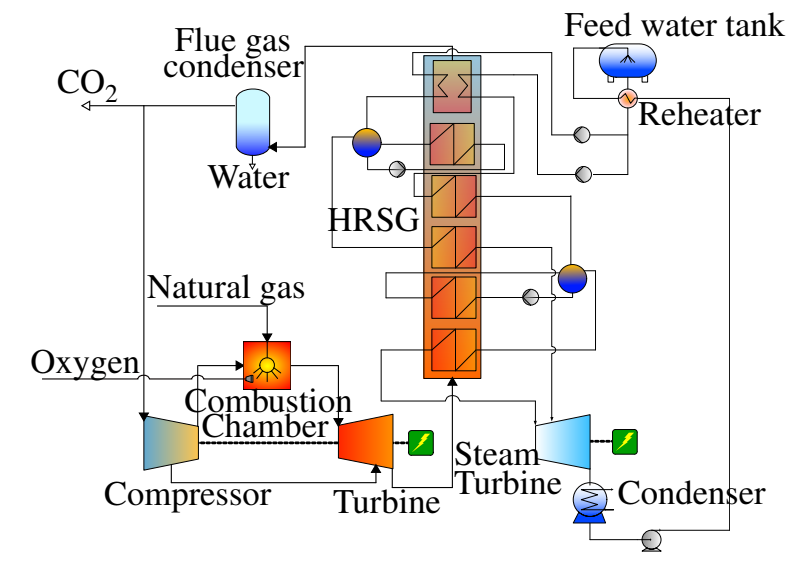

FIGURE 2. PRINCIPLE FLOW SCHEME FOR SCOC-CC.

SCOC-CC The major units in the SCOC-CC are the gas turbine, the heat recovery steam generator, the steam turbines, the flue condenser, the air separation unit, and the $\mathrm{CO}_{2}$ compression train. A schematic of the cycle is shown in Fig. 2. The topping cycle is a Brayton cycle with the working media consisting mainly of $\mathrm{CO}_{2}$. The reason for this composition is that the water is condensed from the flue gas before the major part of the gas, $93 \%$, is recirculated to the compressor. The remaining part of the $\mathrm{CO}_{2}$ is compressed and stored. The cooling media for the turbine is taken from the compressor. The bottoming cycle is a dual-pressure Rankine cycle with steam as a working media. Bolland and Mathieu reported that there is only small difference between a dual- and triple pressure steam cycles [23]. A more detailed description of the cycle can be found in [28].

The results from the cycle analysis are shown in Table 2. Sammak [28] showed that the optimum pressure ratio for the SCOC-CC is 37. The inlet temperature for the compressor is $20^{\circ} \mathrm{C}$ and the pressure is $1.013 \mathrm{bar}$. The exit temperature from the compressor is $394^{\circ} \mathrm{C}$ and from the turbine it is $620^{\circ} \mathrm{C}$. The gross power produced is the power output from the gas turbine and the steam turbines which is $134 \mathrm{MW}$ while the fuel input is $230 \mathrm{MW}$. This means that the gross efficiency of the cycle is $58 \%$. The major energy penalties come from the air separation unit, power required to compress the oxygen, and the power required to compress the carbon dioxide. The production of oxygen reduces the efficiency by $10 \%$. The implication of this high penalty is that further analysis of ASU optimization and integration with the cycles must be carried out. The compression of the carbon dioxide reduces the gross efficiency with another $2 \%$. The resulting net efficiency of the cycle is $46 \%$ and the net power output is $106 \mathrm{MW}$.

Graz cycle The major components in the Graz cycle are the gas turbine, the heat recovery steam generator, the steam turbines, the flue condensers, the compressors on the flue gas, the
TABLE 2. POWER BALANCE FOR THE CYCLES.

\begin{tabular}{llrr}
\hline & Unit & SCOC-CC & Graz cycle \\
\hline Comp. mass flow & $\mathrm{kg} / \mathrm{s}$ & 190 & 62 \\
Comp. pressure ratio & - & 37 & 44.7 \\
Combustor outlet temp. & ${ }^{\circ} \mathrm{C}$ & 1400 & 1400 \\
GT power, Turbine & $\mathrm{MW}$ & 155 & 169 \\
GT power, Compressor & $\mathrm{MW}$ & 67 & 62 \\
Gas turbine power & $\mathrm{MW}$ & 86 & 105 \\
Total heat input & $\mathrm{MW}$ & 230 & 199 \\
Steam turbine power & $\mathrm{MW}$ & 48 & 20 \\
Pumps power & $\mathrm{MW}$ & 0.5 & 0.8 \\
Compressors & $\mathrm{MW}$ & - & 2.9 \\
Gross power output & $\mathrm{MW}$ & 134 & 125 \\
$\mathrm{Gross}$ efficiency & $\%$ & 58 & 63 \\
$\mathrm{O}_{2}$ production & $\mathrm{MW}$ & 23 & 20 \\
$\mathrm{CO}_{2}$ compression & $\mathrm{MW}$ & 5 & 4.3 \\
$\mathrm{CO}_{2}$ mass flow & $\mathrm{kg} / \mathrm{s}$ & 14 & 12 \\
$\mathrm{Net}_{\text {power output }}$ & $\mathrm{MW}$ & 106 & 96 \\
$\mathrm{Net}_{\text {efficiency }}$ & $\%$ & 46 & 49 \\
\hline
\end{tabular}

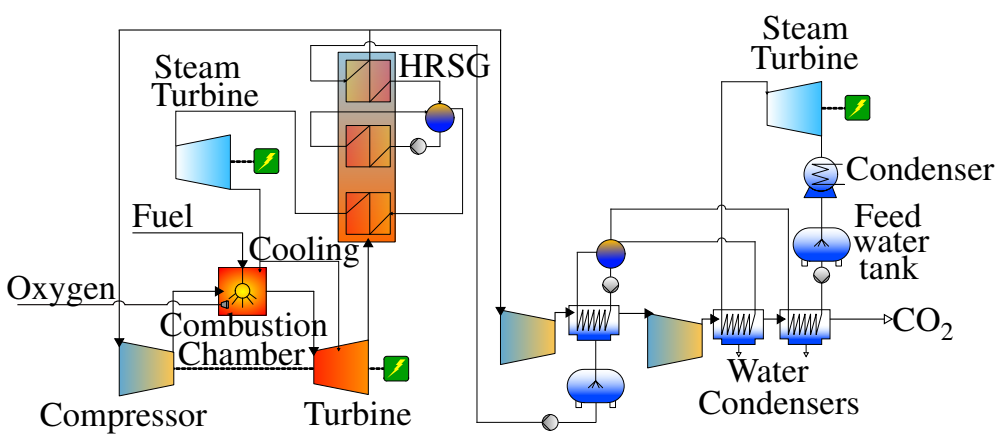

FIGURE 3. PRINCIPLE FLOW SCHEME FOR GRAZ CYCLE.

air separation unit, and the $\mathrm{CO}_{2}$ compression train. A schematic of the cycle is shown in Fig. 3.

The topping cycle is the same as in the SCOC-CC, a Brayton cycle, but with the difference that the main component of the working media is steam. The reason for this is that the part of flue gas that is recirculated to the compressor is not stripped 
from water, as is done in the SCOC-CC. Around half, or 51\%, of the flue gas is recirculated to the compressor. The inlet temperature is $125^{\circ} \mathrm{C}$ and the pressure is 1.06 bar. The exit temperature from the compressor is $710^{\circ} \mathrm{C}$, which indicates a need for an intercooler. The outlet temperature from the turbine is $572^{\circ} \mathrm{C}$. This values are established by the requirement that there cannot be condensed water at the inlet to the compressor. In contrast to the SCOC-CC cycle the Graz cycle uses steam to cool the turbines [9]. Results of a parametric study using the pressure ratio is shown in Fig. 4. The limiting factor for the pressure ratio is the steam used for the cooling in the combustion chamber, and in the gas turbine blades. The net cycle efficiency at the pressure ratio limit is around $48.6 \%$.

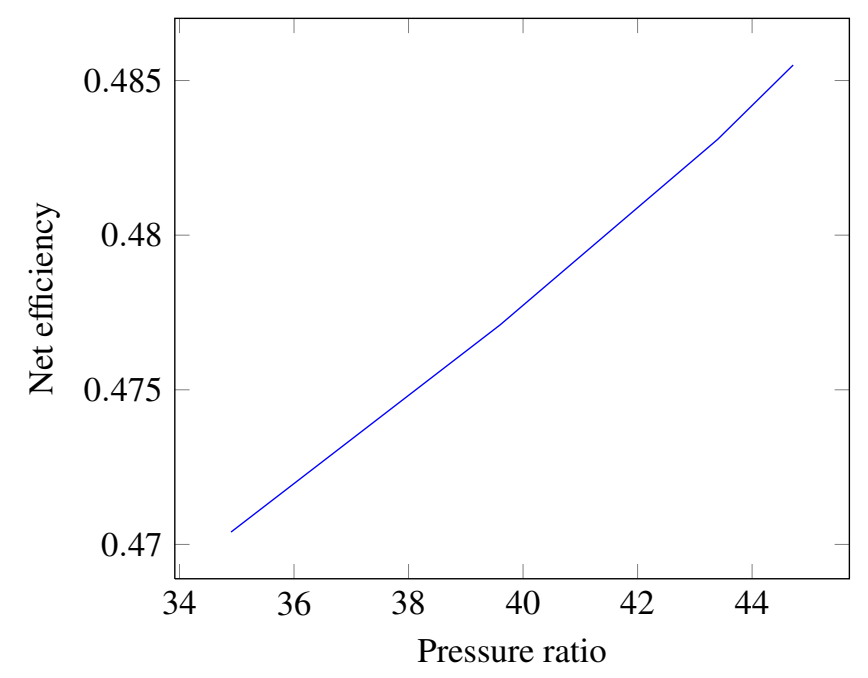

FIGURE 4. PARAMETRIC VARIATION IN THE PRESSURE RATIO FOR THE GRAZ CYCLE.

The Graz cycle has two bottoming cycles. The first extracts the heat from the exhaust gases from the gas turbine while the second uses the heat from the condensation of the water in the flue gas. The first bottoming cycle is a single pressure Rankine cycle. The heat recovery steam generator (HRSG) consists of an economizer, an evaporator and a superheater. The resulting steam that comes from the HRSG has a pressure of $140 \mathrm{bar}$, a temperature of $401^{\circ} \mathrm{C}$ and the mass flow is $33 \mathrm{~kg} / \mathrm{s}$. The steam is then expanded in a turbine, that produces $6.7 \mathrm{MW}$, to a temperature of $261^{\circ} \mathrm{C}$ and a pressure of 47.4 bar. The reason for the high pressure at the exit of the turbine is that the steam is used for cooling in the gas turbine.

The second bottoming cycle is also a single pressure Rankine cycle, but the pressure is sub-atmospheric. The steam generator also consists of an economizer, an evaporator and a superheater but the heat now comes from the condensation of water in the flue gas. The flue gas stream has two compressors producing a flue gas that is above atmospheric conditions. The pressure after the steam generator is $0.73 \mathrm{bar}$, the temperature is $134^{\circ} \mathrm{C}$ and the mass flow is $32 \mathrm{~kg} / \mathrm{s}$. The turbine produces $13 \mathrm{MW}$ by expanding the steam to a pressure of 0.025 bar and a temperature of $21^{\circ} \mathrm{C}$.

The results from the thermodynamic simulation of the cycle is shown in Table 2. The gross output from the cycle is 125 MW and the energy input into the cycle is $199 \mathrm{MW}$. This results in a gross efficiency of $63 \%$. The major energy penalty is the oxygen production with an efficiency penalty of $10 \%$ and the $\mathrm{CO}_{2}$ compression takes further $2 \%$. The resulting net efficiency of the cycle is $49 \%$ accounting for auxiliary systems. The net power output from the cycle is $96 \mathrm{MW}$.

\section{Turbomachinery design}

The difference in the working fluid properties results in an interesting aspect for the sizes of the turbomachinery in the topping cycles. The working fluids in the cycles have similar specific heat ratio while the gas constant and the mean specific heat are around twice as large for the working fluid in the Graz cycle. Using the non-dimensional mass flow equation, Eq. 4, and assuming that the pressure, Mach number and ratio of specific heats are same, it is revealed that the mass flow per area for the SCOC-CC cycle is 1.4 the mass flow per area for the Graz cycle.

$$
\frac{\dot{m} \sqrt{\gamma R T}}{A p}=\gamma M\left(1+\frac{\gamma-1}{2} M^{2}\right)^{-\frac{1}{2}\left(\frac{\gamma+1}{\gamma-1}\right)}
$$

Since the specific heat ratios for the two cycles are of the same order it means that a similar pressure ratio would require a similar change in temperature for a given inlet temperature. However, since the specific heat is approximately twice as large for the Graz cycle it means that the power requirement to achieve a given pressure ratio is approximately twice of that needed for the SCOC-CC. This leads to the conclusion that similar compressor and turbine stage numbers are expected assuming similar Mach number levels. However, the power output for a given mass flow in the Graz cycle is more than double due to the approximately double specific heat. Theoretically, the combined effect of a higher specific heat but a lower mass flow per annulus flow area, combine into an expected $40 \%$ reduction of annulus flow area for the Graz cycle for a given gas turbine power output requirement. However, the optimization of the two cycles leads to differences in overall pressure ratios. In addition, differences in compressor inlet temperature lead to differences in compressor power requirement and turbine stress limitations lead to differences in compressor aerodynamic constraints. 


\section{Conceptual compressor design}

Designing for a high stage loading decreases the number of stages needed to achieve the required pressure ratio. This will in turn reduce the size, weight and production cost of the compressor. However, increasing the stage loading will influence the compressor efficiency and stall margin adversely. This is manifested in a high amount of diffusion generating thick boundary layers along the compressor blade surfaces and which may in the end result in flow separation. During the optimization process the diffusion factor is constrained to be below 0.6 in order to ensure the aerodynamic stability of the compressor [29]. Since the loss models relate the diffusion factors to the efficiency this constraint was not active for the final design solution. An upper limit of 0.45 was set on the stage loading [29]. As will be discussed this constraint is active for some of the compressors studied, depending on the number of stages assumed. The hub to tip radius ratio at the exit of the compressors is constrained to a maximum value of 0.92 as the end wall losses tend to become very high at higher values [30].

The tip clearance to height ratio of the blades has a typical range of $0.5 \%$ at the front stages $1.5 \%$ in the rear stages of a compressor in a stationary gas turbines. However typical stationary mid-sized gas turbines have pressure ratio in the range of 20 to 30 . The pressure ratio for the gas turbines for the SCOC$\mathrm{CC}$ and the Graz cycle are 37 and 44.7 respectively, so the rear stages of the compressors will have considerably higher operating temperatures. This is likely to increase the minimum amount of clearance needed. In this study we assumed that the minimum clearance possible to achieve is $0.6 \mathrm{~mm}$.

The static pressure rise computed with Koch method showed reasonable numbers for all compressors design, although the chord lengths chosen in this analysis may be on the optimistic side.

SCOC-CC The inlet flow is designed with an axial Mach number of 0.6 and a relative tip Mach number of 1.35. These high Mach numbers come from the constraint that the hub to tip radius ratio at the inlet should be higher than 0.35 , to allow sufficient space for the disks. Such aggressive values may be accounted for using a first stage blisk. Advanced design methods using pre-compression s-shaped blade passage ducts could allow for even higher relative Mach numbers. However, the added design complexity and the fact that the underlying loss models assumes profile families that are not feasible in such Mach number ranges, makes such solutions outside the scope of this paper.

Three compressors with 14, 15 and 16 stages respectively were optimized under the constraints given above. The maximum efficiency was established by determining optimal values on the stage loading and degree of reaction. The resulting efficiencies are shown in Table 3. It can be seen that as the number of stages increases the efficiency increases. However the rate of im-

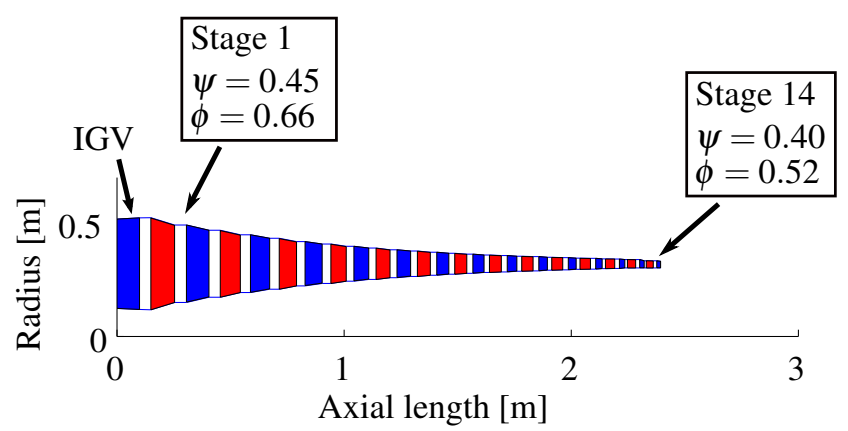

FIGURE 5. 14 STAGE SCOC COMPRESSOR (RED BLADES ARE ROTORS AND BLUE BLADES ARE STATORS).

provement drops off quickly after 16 stages providing a marginal benefit as the number of stages are increased. The annulus for the 14 stage compressor is shown in Fig. 5.

The results for the flow coefficient and stage loading can be seen in Fig. 6. As seen in the figure the stage loading constraint is active for all stages apart from the two last stages in the 14-stage compressor. The reason why the optimizer chooses to reduce the load on these stages is that higher loading would result in a higher diffusion factor. Since the tip clearance to height ratio is highest at the back end of the compressor, 0.04, the penalty for increasing the diffusion on these stages will be prohibitive. As the stage number is increased to 16 all but three stages are unconstrained indicating that further increase in stage numbers may only marginally increase efficiency through a reduced stage load. At the same time increasing stage numbers further will increase the wetted area and increase losses.



FIGURE 6. FLOW COEFFICIENT VS. STAGE LOADING FOR SCOC-CC COMPRESSORS 


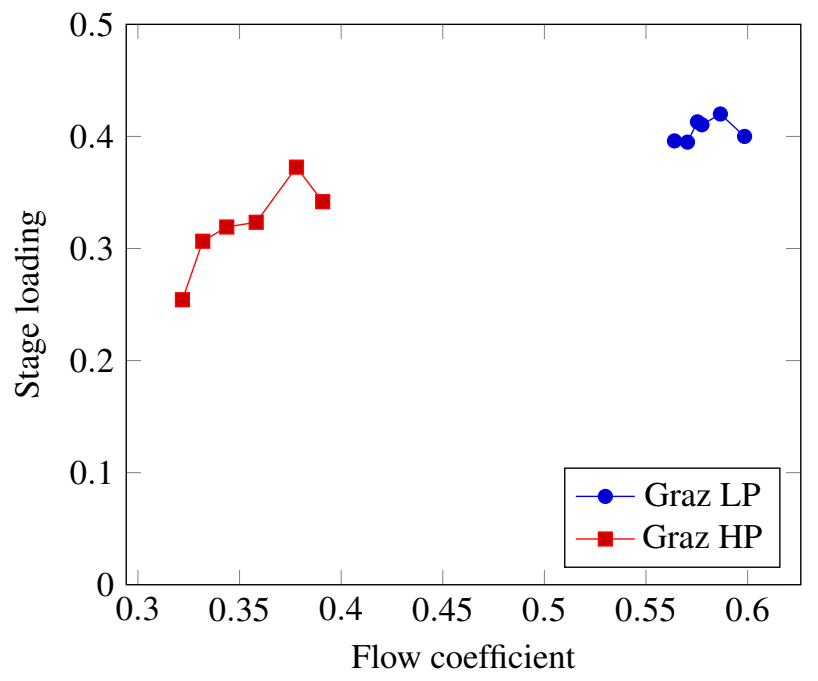

FIGURE 7. FLOW COEFFICIENT VS. STAGE LOADING FOR GRAZ COMPRESSORS

TABLE 3. EFFICIENCIES, PRESSURE RATIOS AND ROTATIONAL SPEEDS FOR THE COMPRESSORS.

\begin{tabular}{lccccc}
\hline & \# stages & $\eta_{s}$ & $\eta_{p}$ & $P R$ & $N$ \\
\hline SCOC & 14 & 86.9 & 89.4 & 37 & 7200 \\
SCOC & 15 & 87.5 & 89.9 & 37 & 7200 \\
SCOC & 16 & 87.9 & 90.3 & 37 & 7200 \\
Graz - LP & 6 & 87.0 & 88.8 & 6.8 & 9000 \\
Graz - HP & 6 & 84.1 & 85.7 & 6.6 & 27000 \\
\hline
\end{tabular}

Graz cycle A first estimate on the number of stages needed for the Graz compressor can be obtained by means of a simplified analysis. From a hub to tip radius ratio of 0.92 at the exit and the area needed to pass the mass flow the exit mid radius can be estimated. If a constant mean radius design is assumed running at a stage loading of 0.45 the number of stages needed is around 36 . Note that the rotational speed is fixed from the maximum root stress condition, $A N^{2}$, of the last stage turbine rotor. This number of compressor stages is viewed as infeasible both in terms of cost and and in terms of compressor starting and operation. The only way to circumvent this constraint is to introduce a geared compressor. Since we are studying a mid-sized cycle and the shaft power requirement therefore is moderate, it is feasible to design a gearbox to drive the compressors. The gearbox can be introduced either into the compressor driving a twin shaft compressor configuration or simply to drive a single shaft compressor.

A single shaft compressor was analysed. The resulting number of stages were at least 22 to achieve the pressure ratio, but to achieve a maximum efficiency around 25 stages are estimated. This is still not a very compact compression system. Here we suggest to use a twin shaft compressor. The relative tip Mach number at the first rotor of the low pressure and high pressure compressors are 1.16 and 1.1 respectively. The low pressure compressor will revolve with $9000 \mathrm{rpm}$ while the high pressure compressor will rotate with $27000 \mathrm{rpm}$. Both compressors have 6 stages and the polytropic efficiency for the low pressure compressor is $88.8 \%$ and for the high pressure compressor the efficiency is $85.7 \%$. Further optimization should enhance the polytropic efficiency up to $90 \%$, but could increase the number of stages. The efficiencies and the pressure ratio for the compressors are given in Table 3. The flow coefficient and the stage loading for the compressors are shown in Fig. 7. The resulting design has not been optimized and the cycle results for this configuration are based on estimates of achievable efficiencies.

\section{Conceptual turbine design}

SCOC-CC The SCOC-CC turbine has been studied by Sammak [22]. The resulting turbine has a rotational speed of $7200 \mathrm{rpm}$ and the power turbine has rotational speed of 3000 rpm. The compressor turbine has two stages and the power turbine has three stages. The root stress at the exit of the compressor turbine $38 \cdot 10^{6} \mathrm{~m}^{2} \mathrm{rpm}^{2}$ which is within design practice. The metal temperature was set to $950^{\circ} \mathrm{C}$ and the cooling mass flow was $44 \mathrm{~kg} / \mathrm{s}$. The metal temperature is high in comparison to current stationary gas turbines. The oxy-fuel turbine is still under development and it is assumed that single crystal alloys will be used in the turbine. Current research has shown that single crystal alloys can handle up to $1000^{\circ} \mathrm{C}[31,32]$.

Graz cycle The twin-shaft gas turbine consists of a gas generator and a free-power turbine. The selection of the rotational speed is constrained with the blade root stress which is limited to $55 \cdot 10^{6} \mathrm{~m}^{2} \mathrm{rpm}^{2}$. The gas generator rotation speed is set to $9000 \mathrm{rpm}$. The free-power turbine rotation speed is set to $6000 \mathrm{rpm}$. Thus the free power turbine is connected to the generator through a reduction gearbox. The design of the turbine takes into account the last stage exit Mach number and stage loading. The conceptual design of the Graz turbine results in a high-pressure turbine with three stages and a power turbine with four stages. The inlet Mach number is 0.12 while the last stage exit Mach number is calculated to be 0.48 . The exit stage loading is 1.2 and exit swirl angle is $-5^{\circ}$. These values are within 


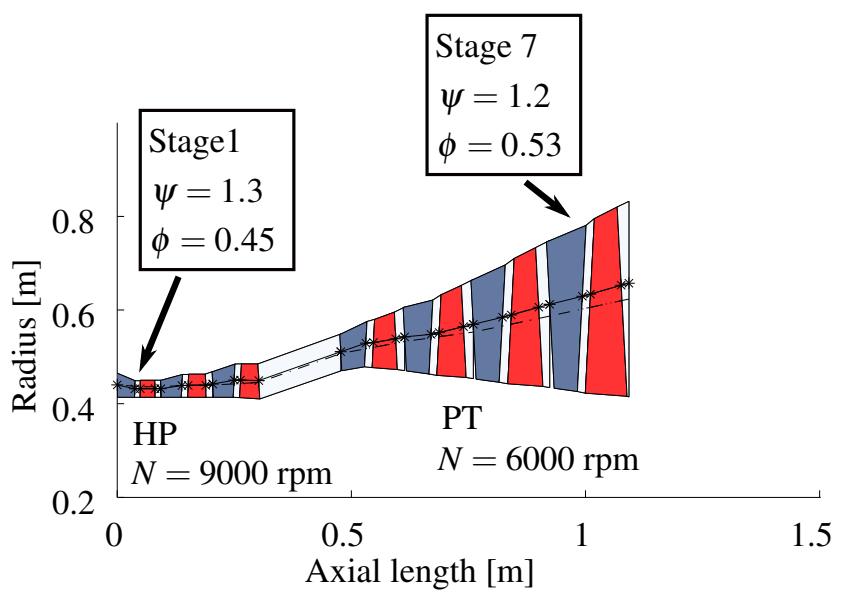

FIGURE 8. GRAZ TURBINE (RED BLADES ARE ROTORS AND BLUE BLADES ARE STATORS).

TABLE 4. KEY TURBINE PARAMETERS FOR GRAZ CYCLE HIGH PRESSURE TURBINE (HP) AND POWER TURBINE (PT).

\begin{tabular}{lcccccc}
\hline Turbine & Stage & $\psi=\frac{\Delta H}{U^{2}}$ & $\phi=\frac{C_{m}}{U}$ & PR & $\Lambda_{p}$ & $\frac{\varepsilon_{s t r}}{\varepsilon_{r t r}}$ \\
\hline \multirow{3}{*}{ HP } & 1 & 1.3 & 0.45 & 1.50 & 0.30 & $\frac{0.40}{0.29}$ \\
& 2 & 1.2 & 0.45 & 1.50 & 0.38 & $\frac{0.26}{0.18}$ \\
& 3 & 1.2 & 0.45 & 1.60 & 0.34 & $\frac{0.10}{-}$ \\
\hline \multirow{4}{*}{ PT } & 4 & 1.9 & 0.5 & 1.65 & 0.40 & - \\
& 5 & 1.9 & 0.46 & 1.85 & 0.40 & - \\
& 6 & 1.7 & 0.47 & 2.0 & 0.40 & - \\
& 7 & 1.2 & 0.53 & 1.8 & 0.40 & - \\
\hline
\end{tabular}

acceptable limits and suitable for a hot end drive diffuser. The combustion outlet temperature is set to $1400^{\circ} \mathrm{C}$ and the metal temperature is limited to $950^{\circ} \mathrm{C}$. The cooling mass flow is determined to be $18 \mathrm{~kg} / \mathrm{s}$ and the free power turbine is uncooled. The annulus area of the Graz turbine is presented in Fig. 8. The design parameters for the turbine is presented in Table 4. The free power turbine fourth, fifth and sixth stages are heavily loaded, and thus attempting to reducing the free power turbine into a three stage configuration would result in a very high last stage Mach number and stage loading.

\section{DISCUSSION AND CONCLUSION}

This paper has presented a comparison analysis of two oxyfuel combustion cycles. The cycle simulation analysis showed that the Graz cycle has higher efficiency, $49 \%$, compared to $46 \%$ for the SCOC-CC. The higher efficiency of the Graz cycle is though weighed down by the design of the cycle. The Graz cycle has two compressors for the $\mathrm{CO}_{2}$ stream and two bottoming cycles, whereas the SCOC-CC has only one bottoming cycle. This makes the Graz cycle more complex.

The turbomachinery was designed for both cycles. The design of the turbine turbine that drives the compressor in the Graz cycle has one more stage than the SCOC-CC turbine which was designed with two stages. The designs for the power turbines for the cycles showed that the turbine for the Graz cycle also needed an extra stage compared to the three stages in the SCOC-CC turbine. The turbines designs for both cycles can be designed well within industrial design practice ranges.

The conceptual design of the compressors resulted in compressor for the SCOC-CC that has 14 stages. To design a compressor for the Graz cycle which has a gas path that maintains a high blade velocity throughout the compressor a geared configuration is expected to be necessary which is quite feasible in this power range. Both a twin-shaft compressor and a single shaft geared configuration are feasible but the twin-shaft configuration is considerably more compact and has a number of stages which is comparable with the optimal SCOC-CC design.

\section{ACKNOWLEDGMENT}

This research has been funded by the Swedish Energy Agency, Siemens Industrial Turbomechinery AB, Volvo Aero Corporation and the Royal Institute of Technology through the Swedish research program TURBOPOWER. The support of which is gratefully acknowledged.

\section{REFERENCES}

[1] Ulizar, I., and Pilidis, P., 1997. "A semiclosed-cycle gas turbine with carbon dioxide-argon as working fluid". Journal of engineering for gas turbines and power, 119, p. 612.

[2] Jericha, H., Sanz, W., and Göttlich, E., 2008. "Design concept for large output Graz cycle gas turbines". Journal of Engineering for Gas Turbines and Power, 130, p. 011701.

[3] Jericha, H., Sanz, W., and Göttlich, E., 2007. "Gas Turbine With $\mathrm{CO}_{2}$ Retention-400 MW Oxy-Fuel System Graz Cycle". CIMAC Paper.

[4] Jericha, H., Sanz, W., Göttlich, E., and Neumayer, F. "Design details of a $600 \mathrm{MW}$ Graz cycle thermal power plant for $\mathrm{CO}_{2}$ capture". ASME Turbo Expo 2008: Power for Land, Sea and Air, 9-13 June.

[5] Bolland, O., Kvamsdal, H., and Boden, J., 2001. "A Thermodynamic Comparison of the Oxy-Fule Power Cycles, Water-cycle, Graz-Cycle and Matiant-Cycle”. In Power generation and sustainable development. International conference, pp. 293-298. 
[6] Celano, A., 2002. "Comparison of near Zero $\mathrm{CO}_{2}$ Emission Power Plants on $\mathrm{CO}_{2} / \mathrm{H}_{2} \mathrm{O}$ Mixture". $\mathrm{PhD}$ thesis, University of Padua.

[7] Franco, F., Mina, T., Woolatt, G., Rost, M., and Bolland, O., 2006. "Characteristics of Cycle Components for $\mathrm{CO}_{2}$ Capture". In Proceedings of 8th International Conference on Greenhouse Gas Control Technologies, Trondheim, Norway.

[8] Woollatt, G., and Franco, F., 2009. "Natural gas oxy-fuel cycles-Part 1: Conceptual aerodynamic design of turbomachinery components". Energy Procedia, 1(1), pp. 573580.

[9] Sanz, W., Jericha, H., Bauer, B., and Göttlich, E., 2008. "Qualitative and Quantitative Comparison of Two Promising Oxy-Fuel Power Cycles for CO Capture". Journal of Engineering for Gas Turbines and Power, 130, p. 031702.

[10] Hendriks, C., de Visser, E., Jansen, D., Carbo, M., Ruijg, G., and Davison, J., 2009. "Capture of $\mathrm{CO}_{2}$ from mediumscale emission sources". Energy Procedia, 1(1), pp. 14971504.

[11] Tech, S., 2003. "IPSEpro process simulator". User Documentation: Program Modules and Model Libraries, SimTech.

[12] Lemmon, E., McLinden, M., and Huber, M., 2007. "REFPROP: reference fluid thermodynamic and transport properties". NIST Standard Reference Database, 23.

[13] Jordal, K., 2001. "Modeling and performance of gas turbine cycles with various means of blade cooling".

[14] Wright, P., and Miller, D., 1992. "An improved compressor performance prediction model".

[15] Schwenk, F., Lewis, G., and Hartmann, M., 1957. A preliminary analysis of the magnitude of shock losses in transonic compressors. NASA RM E57A30.

[16] Xu, L., 2011. "Analysis and Evaluation of Innovative Aero Engine Core Concepts". PhD thesis, Chalmers University of Technology.

[17] Koch, C., 1981. "Stalling pressure rise capability of axial flow compressor stages". Journal of Engineering for Power, 103(4), pp. 645-656.

[18] Dixon, S. L., and Hall, C. A., 2010. Fluid Mechanics and Thermodynamics of Turbomachinery. ButterworthHeinemann.

[19] Mallen, M., and Saville, G., 1977. "Polytropic Processes in the Performance Prediction of Centrifugal Compressors". Paper No. CI83/77, Institution of Mechanical Engineers, London, United Kingdom, pp. 89-96.

[20] Aungier, R., 2003. Axial-flow compressors: a strategy for aerodynamic design and analysis. ASME PRESS.

[21] Moustapha, H., Zelesky, M., Baines, N., and Japikse, D., 2003. Axial and radial turbines. Concepts NREC.

[22] Sammak, M., Genrup, M., Thorbergsson, E., and Grönstedt, T., 2012. "Single and twin-shaft oxy-fuel gas turbine design in a mid-size semi-closed oxy-fuel combustion combined cycle". ASME Turbo Expo 2012: Power for Land, Sea and Air, 11-15 June.

[23] Bolland, O., and Mathieu, P., 1998. "Comparison of two $\mathrm{CO}_{2}$ removal options in combined cycle power plants". Energy Conversion and Management, 39(16), pp. 1653-1663.

[24] Allam, R., White, V., Ivens, N., and Simmonds, M., 2005. "The oxyfuel baseline: revamping heaters and boilers to oxyfiring by cryogenic air separation and flue gas recycle". Carbon Dioxide Capture for Storage in Deep Geologic Formations-Results from the $\mathrm{CO}_{2}$ Capture Project, 1 , p. 451.

[25] Darde, A., Prabhakar, R., Tranier, J., and Perrin, N., 2009. "Air separation and flue gas compression and purification units for oxy-coal combustion systems". Energy Procedia, 1(1), pp. 527-534.

[26] Amann, J., Kanniche, M., and Bouallou, C., 2009. "Natural gas combined cycle power plant modified into an $\mathrm{O}_{2} / \mathrm{CO}_{2}$ cycle for $\mathrm{CO}_{2}$ capture". Energy Conversion and Management, 50(3), pp. 510-521.

[27] Sanz, W., Jericha, H., Luckel, F., Göttlich, E., and Heitmeir, F., 2005. "A Further Step Towards a Graz Cycle Power Plant for $\mathrm{CO}_{2}$ Capture". ASME Turbo Expo 2005: Power for Land, Sea and Air.

[28] Sammak, M., Jonshagen, K., Thern, M., Genrup, M., Thorbergsson, E., and Grönstedt, T., 2011. "Conceptual Design of a Mid-Sized, Semi-closed oxy-fuel combustion combined cycle”. ASME Turbo Expo 2011: Power for Land, Sea and Air, 6-10 June.

[29] Dixon, S., and Hall, C., 2010. Fluid mechanics and thermodynamics of turbomachinery. Butterworth-Heinemann.

[30] Walsh, P., and Fletcher, P., 2004. Gas turbine performance. Blackwell Science Inc.

[31] Mukherji, D., and Rösler, J., 2011. "Design Considerations and Strengthening Mechanisms in Developing CoRe-Based Alloys for Applications at $100 \mathrm{C}$ above NiSuperalloys". Advanced Materials Research, 278, pp. 539544.

[32] Sato, A., Chiu, Y., and Reed, R., 2011. "Oxidation of nickel-based single-crystal superalloys for industrial gas turbine applications". Acta Materialia, 59(1), pp. 225240. 